
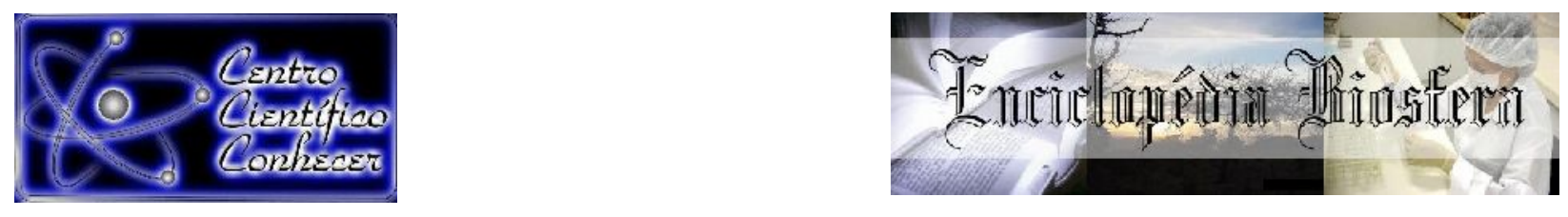

\title{
MORFOLOGIA DE CEPAS DE ACTINOBACTÉRIAS EM ÁREAS SUSCETÍVEIS À DESERTIFICAÇÃO
}

Franciandro Dantas dos Santos ${ }^{1}$, Mariane Pereira Oliveira ${ }^{2}$, Ana Clarice Melo Azevedo de Meneses ${ }^{3}$, Suzana Cláudia Silveira Martins ${ }^{4}$, Claudia Miranda Martins ${ }^{5}$

1. Doutorando do Programa de Pós-graduação em Ecologia e Recursos Naturais na Universidade Federal do Ceará-Campus do Pici, Fortaleza-CE, Brasil. androdsantos@gmail.com

2. Graduanda do Curso de Bacharelado em Agronomia na Universidade Federal do Ceará-Campus do Pici, Fortaleza-CE, Brasil.

3. Doutoranda do Programa de Pós-graduação em Ecologia e Recursos Naturais na Universidade Federal do Ceará-Campus do Pici, Fortaleza-CE, Brasil.

4. Docente na Universidade Federal do Ceará-Campus do Pici, Fortaleza-CE, Brasil.

5. Docente na Universidade Federal do Ceará-Campus do Pici, Fortaleza-CE,Brasil.

Recebido em: 06/04/2019 - Aprovado em: 10/06/2019 - Publicado em: 30/06/2019 DOI: 10.18677/EnciBio_2019A148

\begin{abstract}
RESUMO
A desertificação consiste na degradação em terras secas, resultante de fatores como antropização e a variação climática. No Brasil, as áreas mais susceptíveis à desertificação se localizam na região do semiárido nordestino. Diversas pesquisas estão demonstrando a importância de actinobactérias em serviços ecossistêmicos no semiárido. Características morfológicas como número e posição do esporo são importantes para a classificação de actinobactérias, assim como a microscopia é considerada uma importante ferramenta para a classificação taxonômica desse grupo. Considerando-se a relevância de actinobactérias no semiárido, esse trabalho objetivou investigar seus principais gêneros em áreas suscetíveis a desertificação em diferentes níveis de cobertura vegetal. O gênero Streptomyces foi encontrado com predominância nas três áreas, porém, a área aberta apresentou uma maior diversidade morfológica. Tal fato pode ser justificado pelo fato desse gênero produzir esporos de rápida dispersão em ambientes terrestres.
\end{abstract}

PALVARAS-CHAVE: características morfológicas, cobertura vegetal, semiárido.

\section{MORPHOLOGY OF ACTINOBACTERIA STRAINS OF AREAS SUSCEPTIBLE TO DESERTIFICATION}

\begin{abstract}
Desertification consists of degradation in drylands, resulting from factors such as anthropization and climatic variation. In Brazil, the areas most susceptible to desertification are located in the semiarid region of the Northeast. Several researches are demonstrating the importance of actinobacteria in ecosystem services in the semiarid region. Morphological characteristics such as number and position of the spore are important for the classification of actinobacteria, just as microscopy is considered an important tool for the taxonomic classification of this
\end{abstract}


group. Considering the relevance of actinobacteria in the semiarid region, this work aimed to investigate their main genera in areas susceptible to desertification in different levels of vegetation cover. The genus Streptomyces was found with predominance in the three areas, however, the open area presented a greater morphological diversity. This fact can be justified by the fact that the genus produces rapidly dispersing spores in terrestrial environments.

KEYWORDS: Semi-arid, morphological characteristics, vegetal cover.

\section{INTRODUÇÃO}

A desertificação consiste na degradação em terras secas, resultante de fatores como antropização e a variação climática (UNCCD, 2012). No Brasil, esse processo se restringe ao semiárido nordestino, onde $94 \%$ da área é considerada com moderada à alta suscetibilidade à desertificação (VIEIRA et al., 2015). As regiões semiáridas apresentam características de ambientes áridos, como elevadas temperaturas e altas concentrações de salinidade, além de baixa disponibilidade de nutrientes e escassez de água (DIVITO; SADRAS, 2014; SANTOS et al., 2017).

Ambientes desérticos são típicos de ecossistemas hostis, cuja disponibilidade de água afeta diretamente os organismos (VIKRAM et al., 2016). Entretanto, os microorganismos se adaptam a esses ambientes, afinal conseguem modificar as propriedades físico-químicas da superfície do meio através de suas atividades fisiológicas e metabólicas, além de contribuírem para a formação do solo e na nutrição vegetal. Proteobacteria e Actinobacteria são filos bacterianos encontrados em ambientes áridos (LI et al., 2017), deste último filo pertencem as actinobactérias, micro-organismos que predominam em comunidades microbianas de desertos (SUN et al., 2018).

Pesquisas apontam a ocorrência de actinobactérias em solo da região semiárida (LOPES et al., 2018; MEDEIROS et al., 2018; SOUSA et al., 2018). Estudos com destaque para a produção de enzimas que auxiliam na facilitação já foram documentados nesse ambiente (SILVA et al., 2019). Essa interação pode atuar como um serviço ecossistêmico, visto que tal processo contribui direta e indiretamente na estruturação e funcionamento dos ecossistemas, de forma a garantir a existência da vida, bem como manter às atividades de produção (BURKHARD et al., 2012). Além disso, micro-organismos diazotróficos, como os rizóbios, contribuem para a nutrição das plantas por meio da fixação biológica de nitrogênio (FBN) (SACCÁ et al., 2017) e, interações antagônicas entre actinobactérias e rizóbios oriundos do semiárido, que podem impactar diretamente na FBN, também já foram descritas (LIMA et al., 2017; CAVALCANTE et al., 2017).

Algumas cepas de actinobacterias formam estruturas complexas como esporo, cadeia de esporo, esporângio e esporangiósporo. Além disso, o crescimento e modos de ruptura do micélio reverso, a posição do esporo, o número de esporo, sua estrutura superficial, o molde do esporângio, e se o esporangiósporo possui flagelo ou não, são características morfológicas importantes para classificação de actinobactérias (LI et al., 2016), assim como a microscopia é considerada uma importante ferramenta para a classificação taxonômica actinobacteriana a nível de gênero (BARKA et al., 2016).

Diante do exposto, este trabalho objetivou investigar através da comparação das características morfológicas, tipos de hifas e esporos, os principais gêneros de actinobactérias em áreas suscetíveis a desertificação em diferentes níveis de cobertura vegetal, de forma a contribuir para determinação da diversidade, 
registrando a diversidade morfológica através de imagens, para ser utilizada como ferramenta nos estudos desse grupo.

\section{Área de estudo}

\section{MATERIAL E MÉTODOS}

As amostras de solo foram provenientes de áreas suscetíveis à desertificação com diferentes níveis de cobertura vegetal (área aberta, intermediária e conservada). Esse local representa uma mancha inserida na microrregião do Médio Jaguaribe, no Estado do Ceará, e localizada entre os municípios de Jaguaribe, Jaguaretama e Morada Nova, totalizando uma área de $3239.40 \mathrm{~km}^{2}$. O clima dessa região é caracterizado como quente e seco, com precipitações médias de aproximadamente $800 \mathrm{~mm}$, por ano. Apresenta um período seco frequentemente caracterizado pela falta de chuvas, temperaturas médias anuais entre 23 e $27^{\circ} \mathrm{C}$ e insolação média de $2.800 \mathrm{~h}^{2}$ ano $^{-1}$ (SUDENE, 2019). Todas as amostras foram gentilmente cedidas pelo projeto Desert (Evolução da perda de biodiversidade em áreas sob processos de degradação), Chamada de Projetos MEC/MCTI/CAPES/CNPq/FAPs Nº 03/2014.

\section{Actinobactérias}

Foram selecionadas 24 cepas (08 de cada área) a partir de 47 isoladas do solo do Médio Jaguaribe, tendo como principal requisito a diversidade quanto ao aspecto cultural. As cepas foram previamente codificadas como "MJ", indicativo de Médio Jaguaribe, seguido pelo número (MJ01-MJ47). As cepas de actinobactérias selecionadas foram: MJ-01, MJ-06, MJ-10, MJ-14, MJ-29, MJ-32, MJ-33, MJ-36 (área aberta), MJ-02, MJ-03, MJ-07, MJ-08, MJ-18, MJ-19, MJ-37, MJ-38 (área intermediária), MJ-25, MJ-26, MJ-27, MJ-40, MJ-43, MJ-44, MJ-45 e MJ-47 (área conservada). Essas cepas são mantidas em tubos com meio caseína dextrose (CD), a $25^{\circ} \mathrm{C}$ no Laboratório de Microbiologia Ambiental (LAMAB) do Departamento de Biologia da Universidade Federal do Ceará, compondo a Coleção de Cultura de Actinobactérias do Semiárido.

\section{Morfologia celular}

Para observar a morfologia celular das cepas foi utilizado o método de Coloração de Gram, onde foi feito um esfregaço da colônia isolada sobre uma lâmina, posteriormente seco e fixado pela chama. O esfregaço foi submetido sucessivamente a solução de cristal violeta, lavagem com lugol, água corrente, álcool 95ำ GL e solução de fucsina básica por 30 segundos. As lâminas foram visualizadas em microscópio óptico com aumento de 100x.

\section{Análise micromorfológica}

As cepas de actinobactérias foram inoculadas em meio de cultura Caseina Dextrose Ágar (CDA). Retirou-se do meio uma amostra de $1 \mathrm{~cm}$ de diâmetro e fixouse sobre uma lâmina, coberta por uma lamínula, e incubada em B.O.D. por sete dias, $28 \stackrel{\circ}{ } \mathrm{C}$, contendo algodão encharcado com água destilada, necessário para preservar a umidade do ambiente no interior de uma placa de Petri estéril. Passado o período de crescimento, foi preparada uma nova lâmina, onde foi posta a lamínula contendo a impressão das estruturas das cepas e matizada com o corante Lactofenol de Amann (Kern; Blewins, 1999). As lâminas foram observadas com o auxílio de um microscópio óptico com aumento de 100x. Utilizou-se as características morfológicas, tipos de hifas e esporos, para classificar os gêneros 
das cepas de actinobactérias. Essa classificação foi feita por meio de comparação de imagens do Atlas de Actinomicetos, publicado pela Sociedade Japonesa de Actinomicetos e com o trabalho de Arai, 1976. A morfologia das cadeias de esporos foi classificada segundo Dornelas et al. (2017).

\section{Registro fotográfico}

A obtenção das imagens foi realizada com o auxílio de um microscópio óptico com aumento de 100x e uma câmera fotográfica equipada com dois sensores de 12 Megapixels com lentes duplas, grande-angular e teleobjetiva, de aberturas f 1.8 e $f$ 2.8 respectivamente.

\section{RESULTADOS E DISCUSSÃO}

As características morfológicas, micromorfológicas e as estruturas microscópicas das cepas de actinobactérias avaliadas estão dispostas no Quadro 1. Actinobactérias apresentam uma abundante variedade morfológica, podendo ser cocóides como Micrococcus, cocobacilo como Arthrobacter, filamentos fragmentados como Nocardia e hifas filamentosas como Streptomyces (RAJU et al., 2010). Além disso, a morfologia pode se apresentar em formas baciliares e cocobacilos ou filamentosa e baciliares (WILLIAMS et al.,1989). Como pode ser visto no Quadro 1, todas as estruturas descritas foram encontradas no referido estudo.

QUADRO 1- Morfologia e micromorfologia das cepas de actinobactérias da microrregião do Médio Jaguaribe (CE).

\begin{tabular}{|c|c|c|c|c|}
\hline Cepas & Origem & Gênero & Morfologia & Micromorfologia \\
\hline MJ 01 & Área aberta & Streptomyces & $\begin{array}{l}\text { Formas } \\
\text { filamentosas }\end{array}$ & $\begin{array}{l}\text { Emaranhado de hifas, } \\
\text { presença de cocos livres e } \\
\text { filamentos ondulados }\end{array}$ \\
\hline MJ 06 & Área aberta & Actinomadura & Bastonetes & $\begin{array}{l}\text { Presença de filamentos } \\
\text { ondulados e cocos em } \\
\text { cadeias espiraladas }\end{array}$ \\
\hline MJ 10 & Área aberta & Thermomonospora & Bastonetes & $\begin{array}{l}\text { Hifas filamentosas, cocos } \\
\text { livres e em diplococos, } \\
\text { presença de espirais }\end{array}$ \\
\hline MJ 14 & Área aberta & Thermomonospora & Bastonetes & $\begin{array}{l}\text { Hifas filamentosas, cocos } \\
\text { livres e em diplococos, } \\
\text { presença de espirais }\end{array}$ \\
\hline MJ 29 & Área aberta & Nocardia & Bastonetes & $\begin{array}{l}\text { Hifas ramificadas } \\
\text { pequenas cadeias de } \\
\text { cocos }\end{array}$ \\
\hline MJ 32 & Área aberta & Mycobacterium & $\begin{array}{l}\text { Bastonetes e } \\
\text { cocos }\end{array}$ & $\begin{array}{l}\text { Emaranhado de hifas, } \\
\text { filamentos com cocos nas } \\
\text { extremidades }\end{array}$ \\
\hline MJ 33 & Área aberta & Streptomyces & Cocobacilos & $\begin{array}{l}\text { Filamentos ondulados, } \\
\text { cocos em cadeia e cocos } \\
\text { em cadeias de espirais }\end{array}$ \\
\hline MJ 36 & Área aberta & Streptomyces & Cocobacilos & $\begin{array}{l}\text { Filamentos ondulados e } \\
\text { cocos em cadeia }\end{array}$ \\
\hline
\end{tabular}


MJ 02 Área intermediária Streptomyces

MJ 03 Área intermediária Streptomyces

MJ 08 Área intermediária Nocardia

MJ 18 Área intermediária Nocardia

MJ 19 Área intermediária Streptomyces

MJ 21 Área intermediária Streptomyces

MJ 37 Área intermediária Streptomyces

MJ 38 Área intermediária Streptomyces

MJ 25 Área conservada Streptomyces

MJ 26 Área conservada Streptomyces

MJ 27 Área conservada Streptomyces

MJ 40 Área conservada Streptomyces

MJ 43 Área conservada Streptomyces

MJ 44 Área conservada Actinomadura

MJ 45 Área conservada Micrococcos

MJ 47 Área conservada Streptomyces
Bastonetes e cocos livres

Formas filamentosas e cocos

Bastonetes

Formas filamentosas e baciliares

Cocobacilos

Cocobacilos

Cocos e cocobacilos

Bastonetes

Cocobacilos

Bastonetes

Cocos e bastonetes

Emaranhado de cocos

Bastonetes

Bastonetes e cocos

Cocobacilos
Emaranhado de hifas, cocos em cadeia $\mathrm{e}$ estruturas onduladas

Hifas onduladas, cocos em cadeias e cocos em cadeias de espirais

Formas filamentosas e estruturas onduladas

Formas filamentosas, cocos livres e cadeias de cocos

Hifas ramificadas estruturas espiraladas

Formas filamentosas, presença de cocos livres e cocos em cadeias de espirais

Filamentos ondulados e cocos em cadeias de espirais

Emaranhado de hifas, cocos em cadeias de espirais e formas espiraladas

Emaranhado de hifas e cocos em cadeias de espirais

Hifas ramificadas, cocos em cadeias de espirais e formas onduladas

Filamentos ondulados e formas espiraladas

Hifas ramificadas, cocos em cadeias de espirais

Hifas ramificadas e cocos em cadeias de espirais

Hifas ramificadas e cocos em cadeias de espirais

Cocos livres e cocos em diplococos

Formas filamentosas e Cocos

As características morfológicas, micromorfológicas, a morfologia da cadeia de esporos e os prováveis gêneros das cepas oriundas da microrregião do Médio Jaguaribe podem ser observados pelo gráfico em forma de barras (Figuras 1), em 
forma de pizza (Figuras 2, 3, 4 e 5) e pelo registro fotográfico, que abrange imagens do microcultivo (Figuras 6, 7 e 8).

As cepas de actinobactérias apresentaram diferenças em relação as características morfológicas (Figura 1). As estruturas observadas foram as seguintes: emaranhado de cocos com 12,5\% (03 cepas), bastonetes e cocos livres com 16,66\% (04 cepas), cocobacilos com 20,83\% (05 cepas), bastonetes com $29,16 \%$ (07 cepas), formas filamentosas, filamentosas e baciliares, cocobacilos e bastonetes e esféricas com 4,16\%, cada (01 cepa). Esses resultados aproximam-se aos encontrados por Brito et al. (2015), que ao caracterizarem morfologicamente cepas de actinobactérias, isoladas de amostras de solo do Parque Nacional de Ubajara, no Ceará, se depararam com todas essas estruturas.

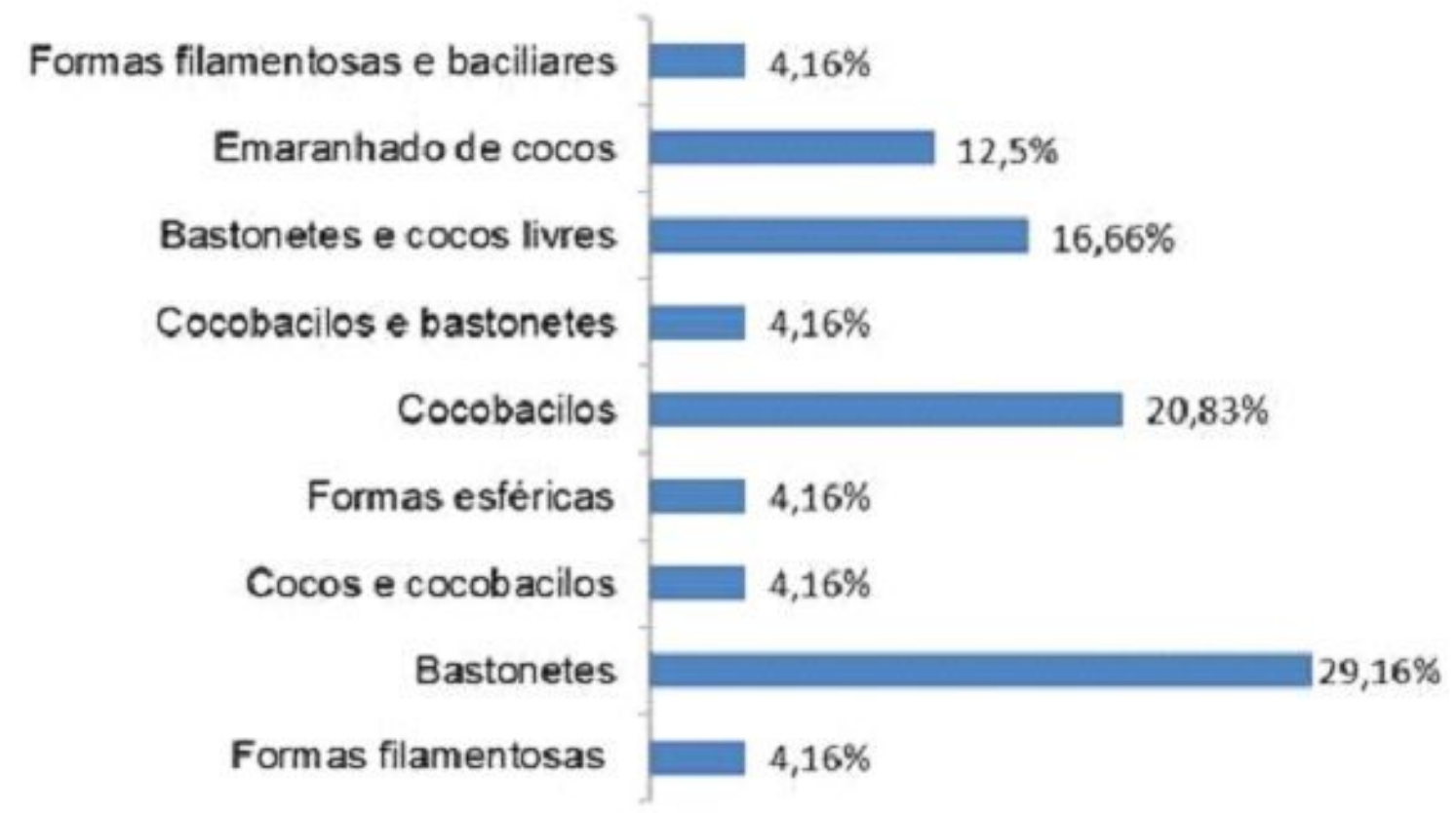

FIGURA 1: Características morfológicas de cepas de actinobactérias oriundas da microrregião do Médio Jaguaribe nas áreas aberta, intermediária e conservada.

O gênero Streptomyces foi encontrado no presente estudo, com predominância nas três áreas, $37 \%$ (aberta), $75 \%$ (intermediária e conservada). Tal fato pode estar associado com a produção de esporos de rápida dispersão em ambientes terrestres (DHARMARAJ, 2010). Em estudo sobre actinobactérias do semiárido nordestino, Lima et al. (2017) agruparam as cepas actinobacterianas nos gêneros Streptomyces e Saccharothrix com base nas características das cadeias de esporos (micromorfológicas). Tais autores afirmaram que os dados da análise de identificação molecular confirmaram os resultados do microcultivo, mesmo procedimento realizado nessa pesquisa.

$\mathrm{Na}$ área aberta foram observados os gêneros Actinomadura (12\%), Mycobacterium (13\%), Nocardia (13\%), Thermomonospora (25\%) e Streptomyces (37\%) (Figura 2). Solos de áreas abertas não possuem cobertura vegetal e, consequentemente estão mais suscetíveis a irradiação solar, apresentando uma maior variação térmica. Liu et al. (2017) mostraram que a temperatura do solo é o fator ambiental que mais afeta a diversidade desse grupo. Entre outros fatores que 
influenciam a variedade de gêneros estão a localização geográfica da área e a estrutura e funcionalidade da comunidade bacteriana, (KNAB et al., 2018).

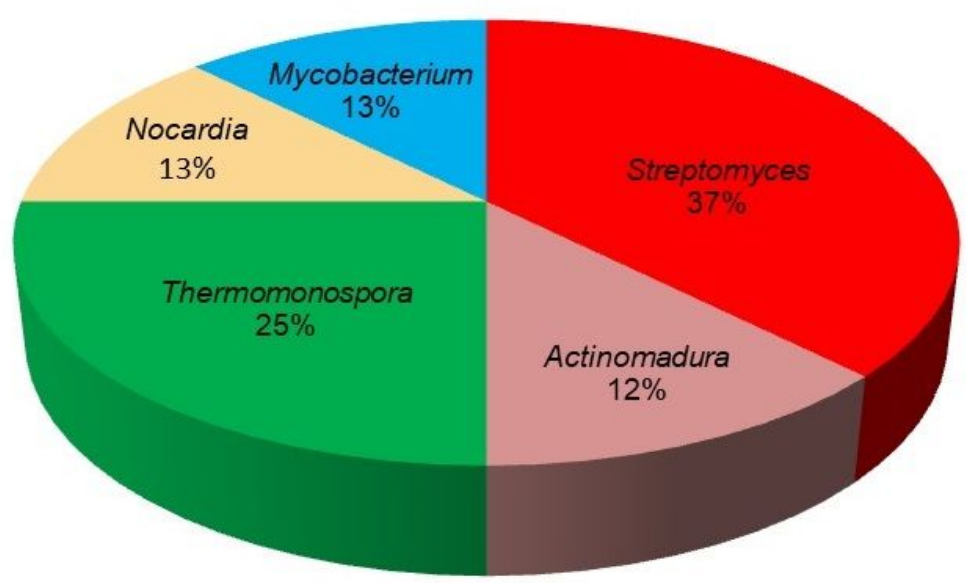

FIGURA 2: Prováveis gêneros de actinobactérias oriundas da microrregião do Médio Jaguaribe na área aberta.

Ao observar a Figura 3, na área intermediária foram encontrados apenas os gêneros Nocardia (25\%) e Streptomyces (75\%). Resultado similar foi constatado por Brito et al. (2015) que ao avaliarem cepas de actinobactérias provenientes de uma Unidade de Conservação inserida no semiárido, encontraram o gênero Streptomyces como mais expressivo, seguido de, Nocardia, Terrabacter e Micromonospora.

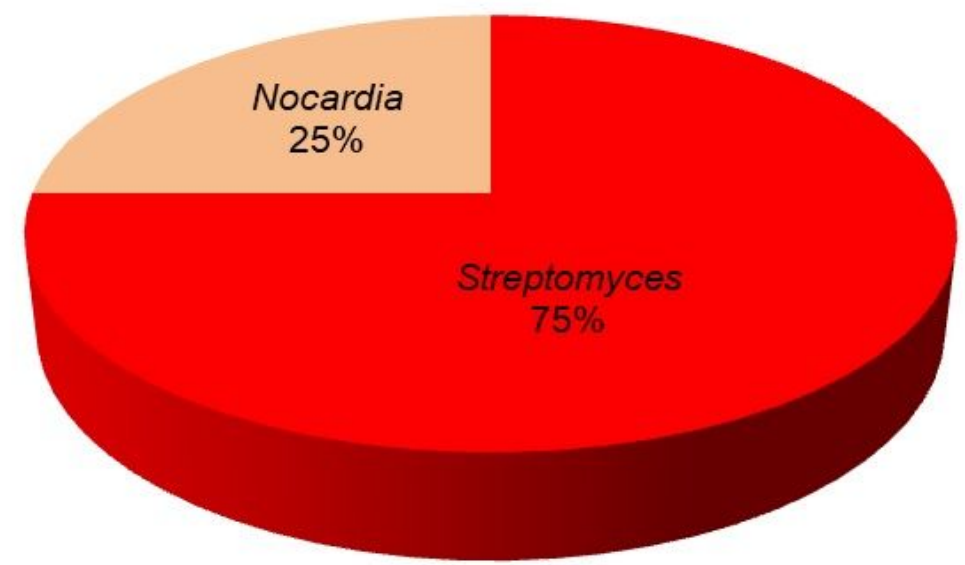

FIGURA 3: Prováveis gêneros de actinobactérias oriundas da microrregião do Médio Jaguaribe na área intermediária.

Analisando a Figura 4, na área conservada, verificaram-se a presença dos gêneros Actinomadura (12\%), Microccocus (13\%) e Streptomyces (75\%). Destacase que o gênero Microccocus foi encontrado apenas nessa área. Segundo AzuaBustos (2014) e Kuo et al. (2017) espécies do gênero Microccocus são facilmente encontradas em ambiente extremos como é o caso de áreas em processo de desertificação. 


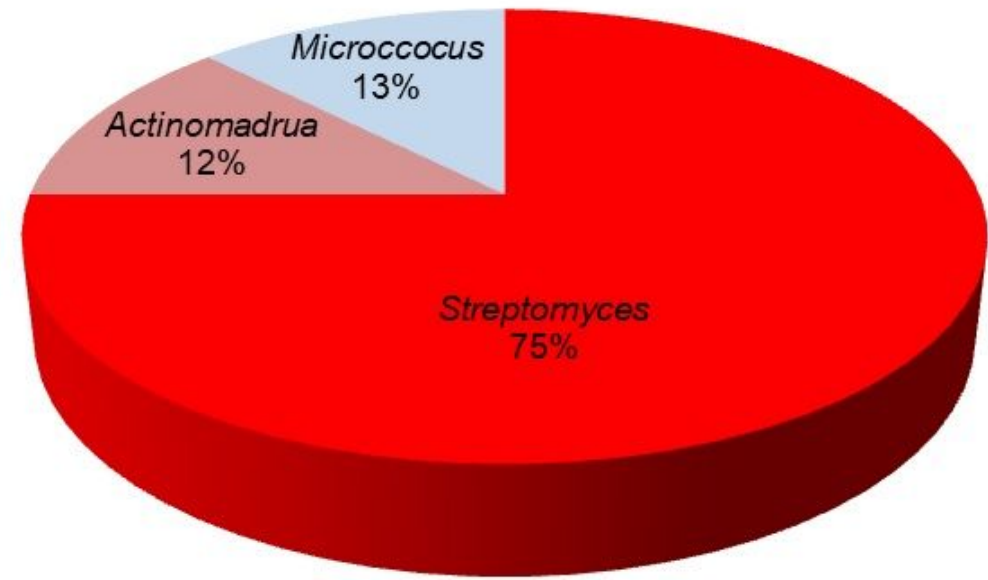

FIGURA 4: Prováveis gêneros de actinobactérias oriundas da microrregião do Médio Jaguaribe na área conservada.

As cepas de actinobactérias apresentaram diferença em relação a morfologia de cadeia de esporos (Figura 3). Na Figura 5, as estruturas predominantes foram flexíveis com 29\% (07 cepas), espiral com 33\% (08 cepas), linha reta 17\% (04 cepas) e retículo $21 \%$ (05 cepas). Variação similar foi constatada por Dornelas et al. (2017), ao documentarem a caracterização morfológica e afiliação filogenética de cepas de actinobactérias de solos tropicas de uma área de cerrado, no Estado de Minas Gerais.

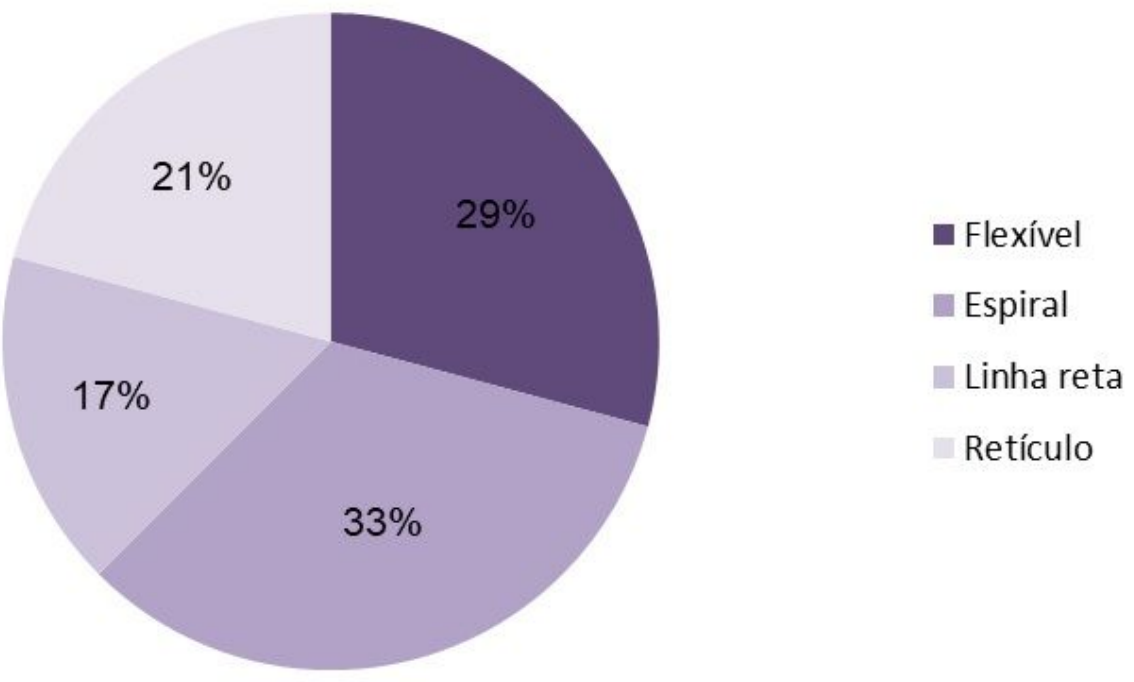

FIGURA 5: Morfologia da cadeia de esporos de actinobactérias oriundas da microrregião do Médio Jaguaribe nas áreas aberta, intermediária e conservada.

Os prováveis gêneros das actinobactérias, bem como a morfologia das cadeias de esporos podem ser utilizados como um parâmetro para auxiliar na classificação taxonômica desse grupo. Os gêneros encontrados nesse trabalho, área aberta (Figura 6), área intermediária (Figura 7) e área conservada (Figura 8) assemelham-se com os descritos por Brito et al. (2015) e Lima et al. (2017). Além disso, às estruturas flexível, espiral, linha reta e retículo das cadeias de esporos foram comparadas com as observadas por Dornelas et al. (2017). 


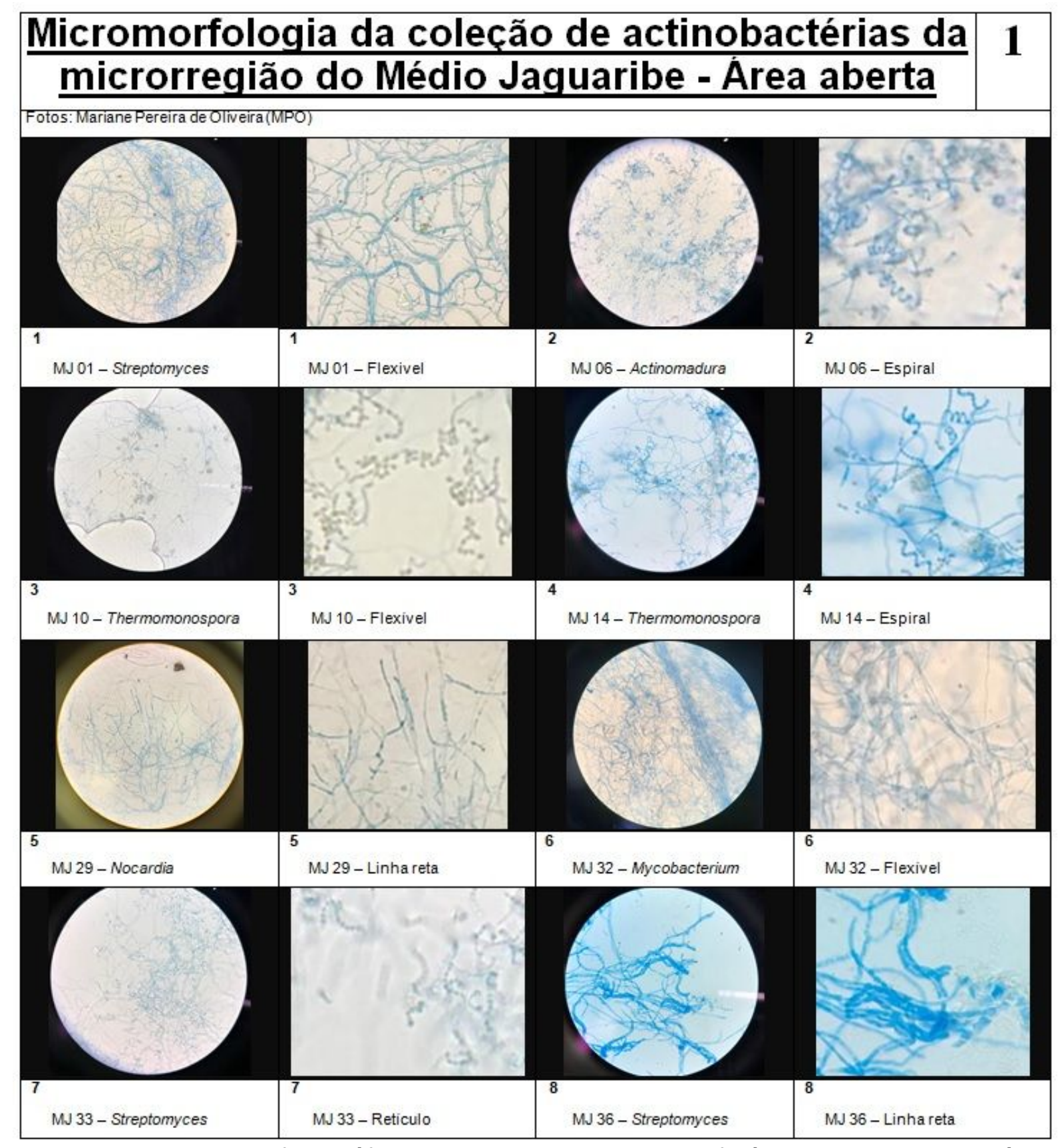

FIGURA 6: Registro fotográfico das estruturas micromorfológicas de actinobactérias oriundas da microrregião do Médio Jaguaribe na área aberta. 


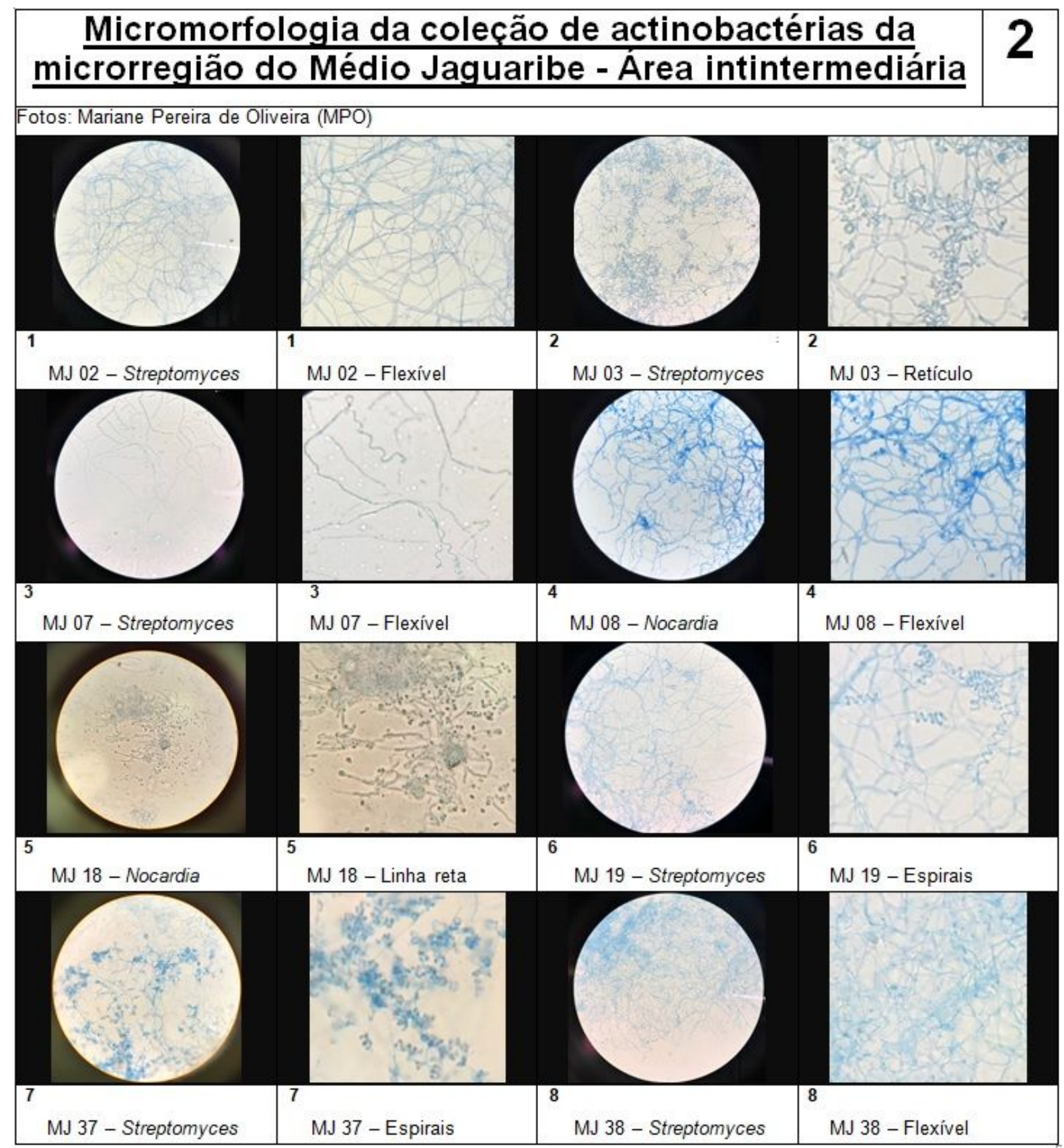

FIGURA 7: Registro fotográfico das estruturas micromorfológicas de actinobactérias oriundas da microrregião do Médio Jaguaribe na área intermediária. 


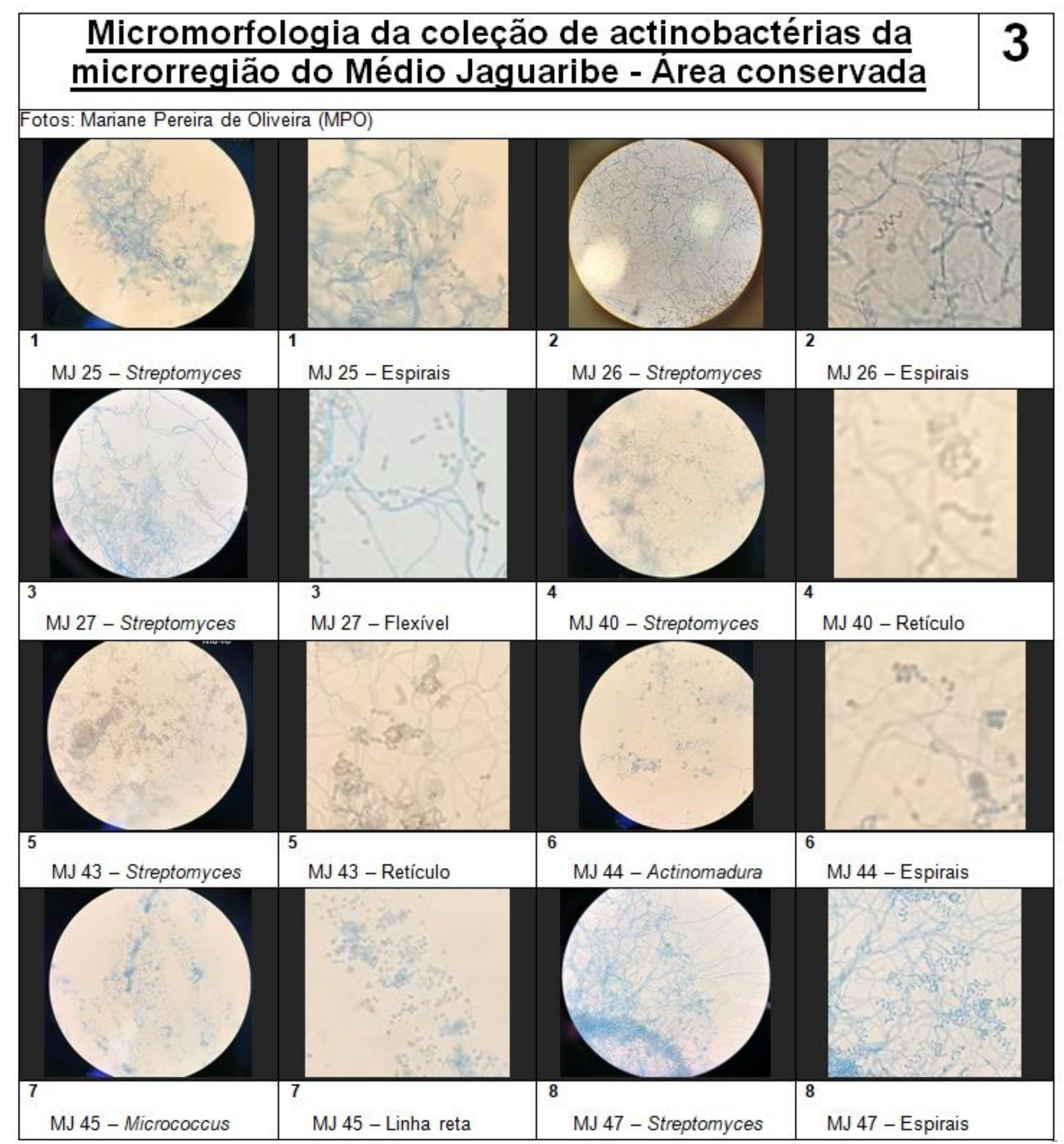

FIGURA 8: Registro fotográfico das estruturas micromorfológicas de actinobactérias oriundas da microrregião do Médio Jaguaribe na área conservada.

\section{CONCLUSÃO}

As cepas de actinobactérias apresentaram morfologia variada nas três áreas com diferentes níveis de cobertura vegetal, com predominância de Streptomyces. A maior diversidade de gêneros foi observada na área aberta. Além disso, o acervo fotográfico poderá ser utilizado como ferramenta de consulta na identificação de novas cepas provenientes da região semiárido.

\section{AGRADECIMENTOS}

O presente trabalho foi realizado com apoio da Coordenação de Aperfeiçoamento de Pessoal de Nível Superior-Brasil (CAPES) - Código de Financiamento 001. 


\section{REFERÊNCIAS}

ARAI, TADASHI. Actinomycetes: the boundary microorganisms. University Park Press, 1976.

AZUA-BUSTOS A.; GONZÁLEZ-SILVA C. Biotechnological applications derived from microorganisms of the Atacama Desert. BioMed research international, 2014. Disponível em: <https://doi.org/10.1155/2014/909312>. DOI: 10.1155/2014/909312.

BARKA, E. A.; VATSA, P.; SANCHEZ, L.; GAVEAU-VAILLANT, N.; JACQUARD, C.; KLENK, $\mathrm{H}$. et al. Taxonomy, Physiology, and Natural Products of Actinobacteria. Microbiology and Molecular Biology Reviews, v. 80, n. 1, p.1-43, 2016. Disponível em: <http://dx.doi.org/10.1128/MMBR.00019-15>. DOI: 10.1128/MMBR.00019-15

BURKHARD, B., DE GROOT, R.; COSTANZA, R., SEPPELT, R.; JORGENSEN, S. E. et al. Solutions for sustaining natural capital and ecosystem services. Ecological Indicators, $\quad$ v.21, $\quad$ p.1-6, $2012 . \quad$ Disponível em: <https://doi.org/10.1016/j.ecolind.2012.03.008> DOI:10.1016/j.ecolind.2012.03.008

BRITO, F. A. E.; RAMOS, K. A.; DA SILVA, R. M.; MARTINS, C. M.; MARTINS, S. C. S. Actinobacteria from rizospheric soil in the caatinga biome. Enciclopédia Biosfera, v.11, n.21, p. 1992-2004, 2015. Disponível em: http://www.conhecer.org.br/enciclop/2015b/biologicas/actinobacterias.pdf

CAVALCANTE, F. G., MARTINS, C. M.; MARTINS, S. C. S. Interações bióticas entre actinobactérias e rizóbios em solos da região semiárida brasileira. Enciclopédia Biosfera, v.14, n.26, p. 2017. Disponível em: < http://www.conhecer.org.br/enciclop/2017b/biol/interacoes\%20Bioticas.pdf> DOI: 10.18677/EnciBio_2017B86

DHARMARAJ, S. Marine Streptomyces as a novel source of bioactive substances. World Journal of Microbiology and Biotechnology, v.26, n.12, p.2123-2139, 2010. Disponível em: <https://link.springer.com/content/pdf/10.1007\%2Fs11274010-0415-6.pdf> DOI: 10.1007/s11274-010-0415-6.

DIVITO, G. A.; SADRAS, V. O. How phosphorus, potassium and sulphur affect plant growth and biological nitrogen fixation in crop and pasture legumes? Field Crop Research, v.156, p.161-171, 2014. Disponível em: $<$ https://doi.org/10.1016/j.fcr.2013.11.004>

DORNELAS, J. C. M.; FIGUEIREDO, J. E. F.; DE ABREU, C. S.; LANA, U. G. P.; OLIVEIRA, C. A. et al. Characterization and phylogenetic affiliation of Actinobacteria from tropical soils with potential uses for agro-industrial processes. Genetics and Molecular Research. v.16, n. 3, 2017. Disponível em: < http://dx.doi.org/10.4238/gmr16039703> DOI: 10.4238/gmr16039703

KNÁB, M.; SZILI-KOVÁCS, T.; MÁRIALIGETI, K., MÓGA, J.; BORSODI, A. K. Bacterial diversity in soils of different Hungarian karst areas. Acta Microbiologica et Immunologica Hungarica, v.65, n.4, p.1-20. 2018. Disponível em: 10.1556/030.65.2018.002>, DOI:10.1556/030.65.2018.002 
KERN, M. E.; BLEVINS, K. S. Micologia Médica: Texto e Atlas. 2 ed. São Paulo:Premier, 1999.

KUO, V.; SHOEMAKER, W. R.; MUSCARELLA, M. E.; WHOLE, J. T. L. Genome sequence of the soil bacterium Micrococcus sp. KBS0714. Genome Announcements, v. 5, n. 32, p. e00697-17, 2017. Disponível em: https://doi .org/10.1128/genomeA.00697-17. DOI: 10.1128/genomeA.00697-17.

LI, Q.; CHEN, X.; JIANG, Y.; CHENGLIN, J. Morphological Identification of Actinobacteria. Actinobacteria. Basics and Biotechnological Applications, [s.I.], p.59-86, 2016. Disponível em: <https://doi.org/10.5772/61461 >. DOl: $10.5772 / 61461$.

LI, F.; JIA, H.; WANG, Y.; TANG, H.; ZHANG, L. Change of Soil Bacteria Diversity between Desertification and Restoration. Journal of Pharmacy and Biological Sciences, v.12, n.1, p.74-87, 2017. Disponível em: < https://www.academia.edu/33832139/Change_of_Soil_Bacteria_Diversity_between_ Desertification_and_Restoration> DOI: 10.9790/3008-1201047487

LIMA, J. V. L.; MARTINS, S. C. S; SIQUEIRA, K. A.; SOARES, M.; MARTINS, C. M. Characterization of actinobacteria from the semiarid region, and their antagonistic effect on strains of rhizobia. African Journal of Biotechnology. v.16, p.499-507, 2017. Disponível em: <https://doi.org/10.5897/AJB2016.15724> DOI: 10.5897/AJB2016.15724

LIU, X.; CONG, J.; LU, H.; XUE; Y.; WANG, X.; et al. Community structure and elevational distribution pattern of soil Actinobacteria in alpine grasslands. Acta Ecologica Sinica, v.37, n.4, p.213-218, 2017. Disponível em: <http://scihub.tw/10.1016/j.chnaes.2017.02.010> DOI: 10.1016/j.chnaes.2017.02.010

LOPES, J. B. A. C., SILVA, V. M. A., CAVAlCANTE, F. G., MARTINS, S. C. S., MARTINS, C. M. Produção de enzimas hidrolíticas extracelulares por actinobactérias oriundas do solo e serrapilheira de região semiárida. Enciclopédia Biosfera, v. 15, n. 27, p. 35-50, 2018.2 Disponível em: <http://www.conhecer.org.br/enciclop/2018a/biol/producao.pdf> 10.18677/EnciBio_2018A93.

MEDEIROS, E. J. T.; CAVALCANTE, F. G.; SILVA, V. M. A.; SILVEIRA, S. C.; MARTINS, C. M. Diversidade cultural de cepas de actinobactérias do semiárido. Enciclopédia Biosfera, v.15, n.27, p.205-218. 2018. Disponível em: < http://www.conhecer.org.br/enciclop/2018a/biol/diversidade.pdf> 10.18677/EnciBio_2018A87

MIYADOH, SE. Atlas of actinomycetes. Society for Actinomycetes Japan, 1997.

RAJU, A.; PIGGOTT, A. M.; CONTE, M.; TNIMOV, Z.; ALEXANDROV, K.; CAPON, R. J. Nocardiopsins: New FKBP12-Binding Macrolide Polyketides from an Australian Marine-Derived Actinomycete, Nocardiopsis sp. Chemistry European Journal, v.16, p.3194 - 3200, 2010. DOI: https://doi.org/10.1002/chem.200902933 
SACCÁ, M. L.; CARACCIOLO, A. B.; DI LENOLA, M.; GRENNI, P.. Ecosystem services provided by soil microorganisms. In Soil Biological Communities and Ecosystem Resilience. Sustainability in Plant and Crop Protection, p. 9-24, 2017. Disponível em: < https://www.researchgate.net/publication/319675441> DOI 10.1007/978-3-319-63336-7_2

SANTOS, C. M.; ENDRES, L.; FERREIRA, V. M.; SILVA, J. V.; ROLIM, E. V.; WANDERLEY FILHO, H. C. L. Photosynthetic capacity and water use efficiency in Ricinus communis (L.) under drought stress in semi-humid and semi-arid areas. Anais da Academia Brasileira de Ciências, v. 89, n. 4, 2017. Disponível em: <http://dx.doi.org/10.1590/0001-3765201720160729>.

SILVA, V. M. A; MARTINS, C. M.; CAVALCANTE, F. G.; RAMOS, K. A.; SILVA, L. L. et al. Cross-Feeding among soil bacterial populations: selection and characterization of potential bio-inoculants. Journal of Agricultural Science, v. 11, n, 5. 2019 (no prelo). URL: https://doi.org/10.5539/

SUDENE.<http://www.sudene.gov.br/acesso-a informa\%C3\%A7\%C3\%A3o/institucional/area-de-atuacao-da sudene/semiarido> Acesso em: 28/03/2019.

SUN, H. M.; ZHANG, T.; YU, L. Y.; KEYA, S.; ZHANG, Y. Q. Ubiquity, diversity and physiological characteristics of Geodermatophilaceae in Shapotou National Desert Ecological Reserve. Frontiers in Microbiology, v. 6, p. 1059, 2015. Disponível em: < https://doi.org/10.3389/fmicb.2015.01059>

VIEIRA, R. D. S. P.; TOMASELLA, J.; ALVALÁ, R. C. S.; SESTINI, M. F.; AFFONSO, A. G., et al. Identifying areas susceptible to desertification in the Brazilian northeast. Solid Earth, v.6, n.1, p.347-360, 2015. Disponível em: < https://doi.org/10.5194/se-6347-2015> DOI.org/10.5194/se-6-347-2015

VIKRAM, S.; GUERRERO, L. D.; MAKHALANYANE, T. P.; LE, P. T.; SEELY, M.; COWAN, D. A. Metagenomic analysis provides insights into functional capacity in a hyperarid desert soil niche community. Environmental Microbiology. v.18, n.6, p.1875-1888, 2016. Disponível em: <https://doi.org/10.1111/1462-2920.13088>

United Nations Convention to Combat Desertification (UNCCD)Regions: Africa, Bonn: UNCCD, available at: http://www.unccd.int/en/regionalaccess/Pages/countries.aspx?place=_31 (last access: 05 May 2013), 2012.

WILLIAMS, S. T.; SHARPE, M.E.; HOLT, J. G. Bergey's Manual of Systematic Bacteriology. New York: Williams e Wilkins, v. 4, 1989, 2648p. 